\title{
Monomorphic post-transplant lymphoproliferative disorder of the tongue: case report and review of literature Luis F Gonzalez-Cuyar ${ }^{1}$, Fabio Tavora ${ }^{1}$, Allen P Burke ${ }^{1}$, Christopher D Gocke ${ }^{1,4}$, Ann Zimrin ${ }^{2}$, John J Sauk ${ }^{3}$ and Xiafeng F Zhao*1
}

\begin{abstract}
Address: ${ }^{1}$ Department of Pathology, University of Maryland School of Medicine, 22 South Greene Street, NBW64, Baltimore, Maryland, USA, ${ }^{2}$ Department of Medicine, University of Maryland School of Medicine, 22 South Greene Street, NBW64, Baltimore, Maryland, USA, ${ }^{3}$ Department of Oral Pathology, University of Maryland School of Medicine, 22 South Greene Street, NBW64, Baltimore, Maryland, USA and ${ }^{4}$ Departments of Pathology and Oncology, Johns Hopkins School of Medicine, Baltimore MD, USA
\end{abstract}

Email: Luis F Gonzalez-Cuyar - luisgonzcuyar@gmail.com; Fabio Tavora - ftavora@gmail.com; Allen P Burke - allen.burke@gmail.com; Christopher D Gocke - gocke1@jhmi.edu; Ann Zimrin - AZIMRIN@umm.edu; John J Sauk - JSauk@umaryland.edu;

Xiafeng F Zhao* - xzhao@umm.edu

* Corresponding author

Published: 19 December 2007

Diagnostic Pathology 2007, 2:49 doi:10.1 186/1746-1596-2-49
Received: 15 October 2007

Accepted: 19 December 2007

This article is available from: http://www.diagnosticpathology.org/content/2/1/49

(C) 2007 Gonzalez-Cuyar et al; licensee BioMed Central Ltd.

This is an Open Access article distributed under the terms of the Creative Commons Attribution License (http://creativecommons.org/licenses/by/2.0), which permits unrestricted use, distribution, and reproduction in any medium, provided the original work is properly cited.

\begin{abstract}
Background: Post-transplant lymphoproliferative disorder (PTLD) is a spectrum of hematological diseases arising in context of immunosuppression after organ transplantation. PTLD can involve any organ; however, it is extremely rare in oral cavity.
\end{abstract}

Methods: Using morphologic and immunophenotypic approaches we have studied a case of monomorphic PTLD of the tongue that developed in a patient following unilateral kidney and pancreas transplantation on immunosuppressive therapy. Additionally, cases of PTLD in the oral cavity were reviewed in the English literature.

Results: The neoplasm showed large cell morphology and B-cell phenotype. In situ hybridization for Epstein-Barr virus was positive. Complete remission was obtained after decreasing immunosuppressive therapy. The patient remained in remission at 790 days' follow up.

Conclusion: This rare case increased our awareness of PTLD in the oral cavity of patients following solid organ transplantation and immunosuppressive therapy.

\section{Introduction}

Post-transplant lymphoproliferative disorder (PTLD) is a well-recognized complication after solid organ or bone marrow transplantation. It comprises a spectrum of pathologic patterns ranging from reactive Epstein-Barr virus (EBV)-driven lymphocytic/plasmacytic hyperplasia to high-grade malignant lymphomas [1]. PTLD may involve the lymph nodes or extranodal tissue at any site, including the organ allograft [2]. A series of 90 PTLD cases occurring in 4283 solid organ transplantations over a nine-year period revealed that two thirds of the patients presented with disease in a single site [3], and none of the cases presented in the tongue at diagnosis. Here we report a rare case of monomorphic PTLD of the tongue in a patient after kidney and pancreas transplantation, which was effectively treated solely by reduction of immunosuppression. Review of the English literature reveals only a few such cases that involve oral cavity (Table 1 ). 
Table I: Literature review of Posttransplant lymphoproliferative disorders (PTLD) arsing in the oral cavity

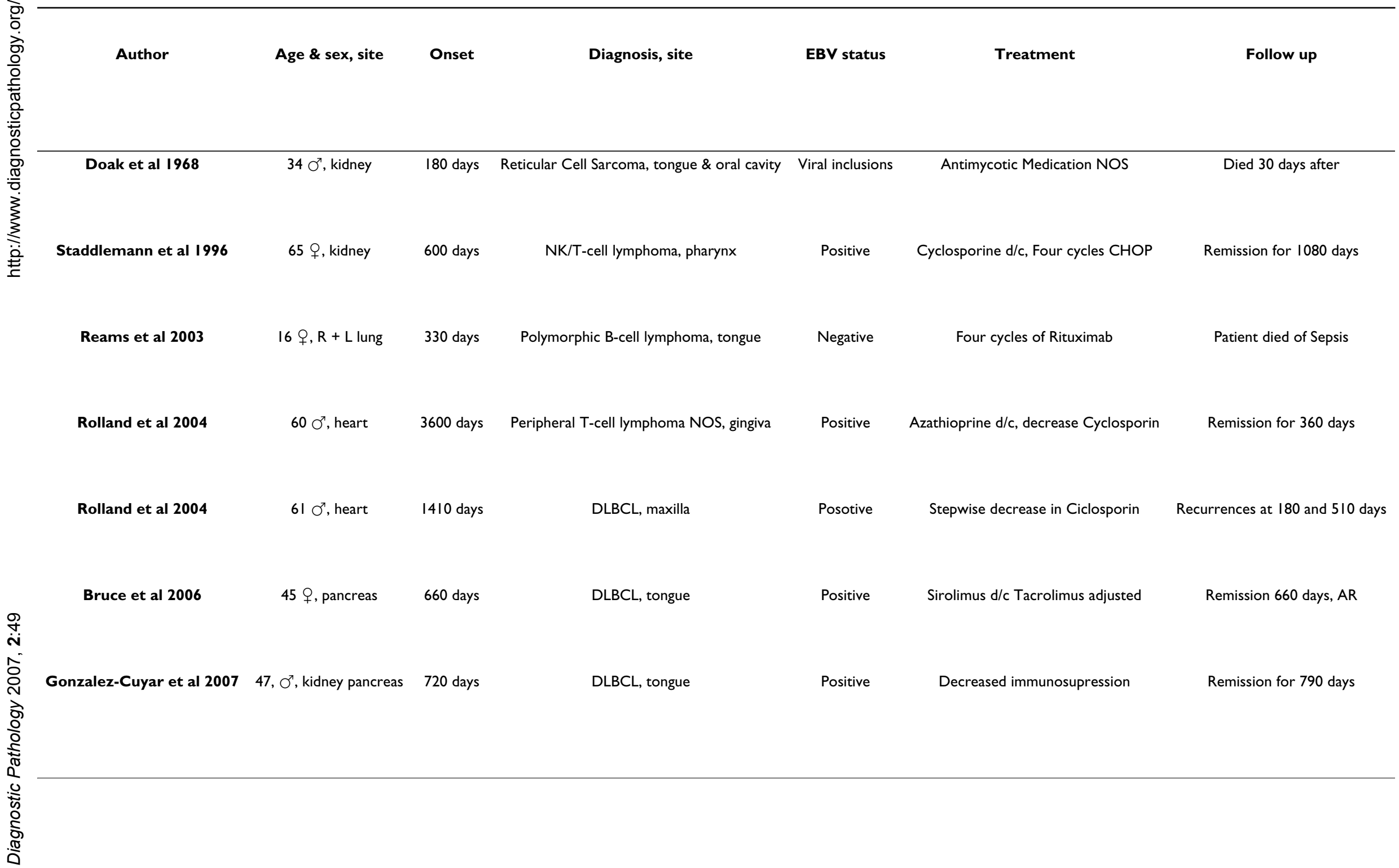




\section{Case presentation}

A 47-year-old Caucasian male with history of Diabetes Mellitus type I underwent simultaneous pancreas-kidney transplantation two years prior to the current admission. Past medical history also included depression and 20 pack-year smoking with cessation 10 years ago. At admission he presented with sore throat, progressive dysphagia, odynophagia, and weight loss. His immunosuppression regimen included tacrolimus $(8 \mathrm{mg} /$ day $)$ and prednisone ( $5 \mathrm{mg} /$ day). The physical exam was remarkable for a $4 \mathrm{~cm}$ exophytic lesion at the right base of tongue that appeared to extend to the inferior pole of the tonsillar fossa, as well as marked right cervical lymphadenopathy. Computed tomographic (CT) scan of the neck revealed an ill-defined mass in the right peripharyngeal region at the base of the tongue with deviation of the airway to the left (Figure 1A). In addition, a conglomerate mass representing a group of involved lymph nodes invading the right sternocleidomastoid muscle was also identified (Figure 1B). CT scan of the abdomen showed enlarged right mesenteric lymph nodes and an area of thickening of the small bowel wall. A panendoscopy with biopsy of the right base of the tongue lesion was performed. The hematoxylin-eosin (H\&E) stained sections showed sheets of monotonous large atypical lymphoid cells with abundant cytoplasm, large vesicular nuclei and occasional prominent nucleoli (Figure 2A). These neoplastic cells infiltrated the adjacent skeletal muscles of the pharynx. Mitotic figures were rare. Large foci of necrosis were noted. Immunohistochemical stains demonstrated that the large cells were positive for CD20 (Figure 2B), CD30, BCL2, CD38 and EBV latent membrane protein (LMP) (Figure $2 \mathrm{C}$ ). CD5 was aberrantly expressed in these cells. These cells were negative for CD3 and CD79a. Staining for immunoglobulin light chains kappa and lambda revealed only a few scattered polyclonal plasma cells. Molecular studies revealed IGH gene rearrangement in the neoplastic cells. Given the patient's history of solid organ transplantation and immunosuppression, it was diagnosed as monomorphic PTLD, consistent with diffuse large B-cell lymphoma. A CT scan of the pancreas and kidneys was negative for tumor. Repeated bone marrow biopsies were also negative for lymphoma involvement.

The immunosuppressive agents were withdrawn and the patient was closely followed. Ten weeks after the cessation of immunosuppressive therapy, the oral lesion had completely regressed and repeated CT scans of the head, neck and abdomen were constantly negative. Subsequent biopsies of the oral cavity were also negative. The patient has been followed for over 790 days and he currently remains in remission on lower doses of immunosuppressants, and with functioning allografts.
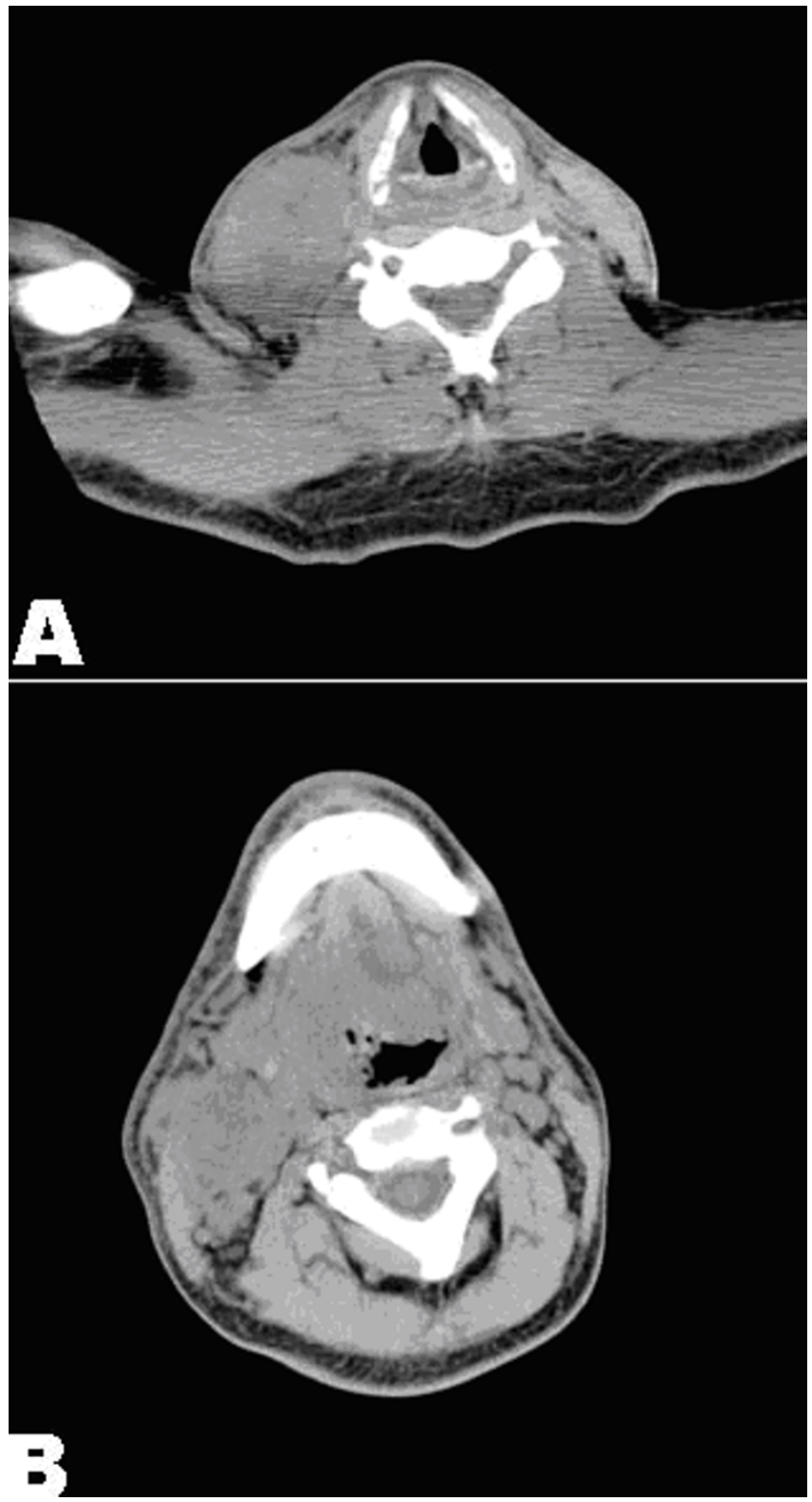

Figure I

Images of computed tomography (CT) without contrast. A. Lesion at the base of tongue (indicated by an arrow); B. Conglomerate mass invading the right sternocleidomastoid muscle (indicated by an arrow).

\section{Discussion}

We have presented a rare case of monomorphic PTLD of the tongue with a complete remission after withdrawal of immunosupression. Through this case, we have also illustrated another successful example of managing the immunodeficiency-associated malignant lymphomas. 


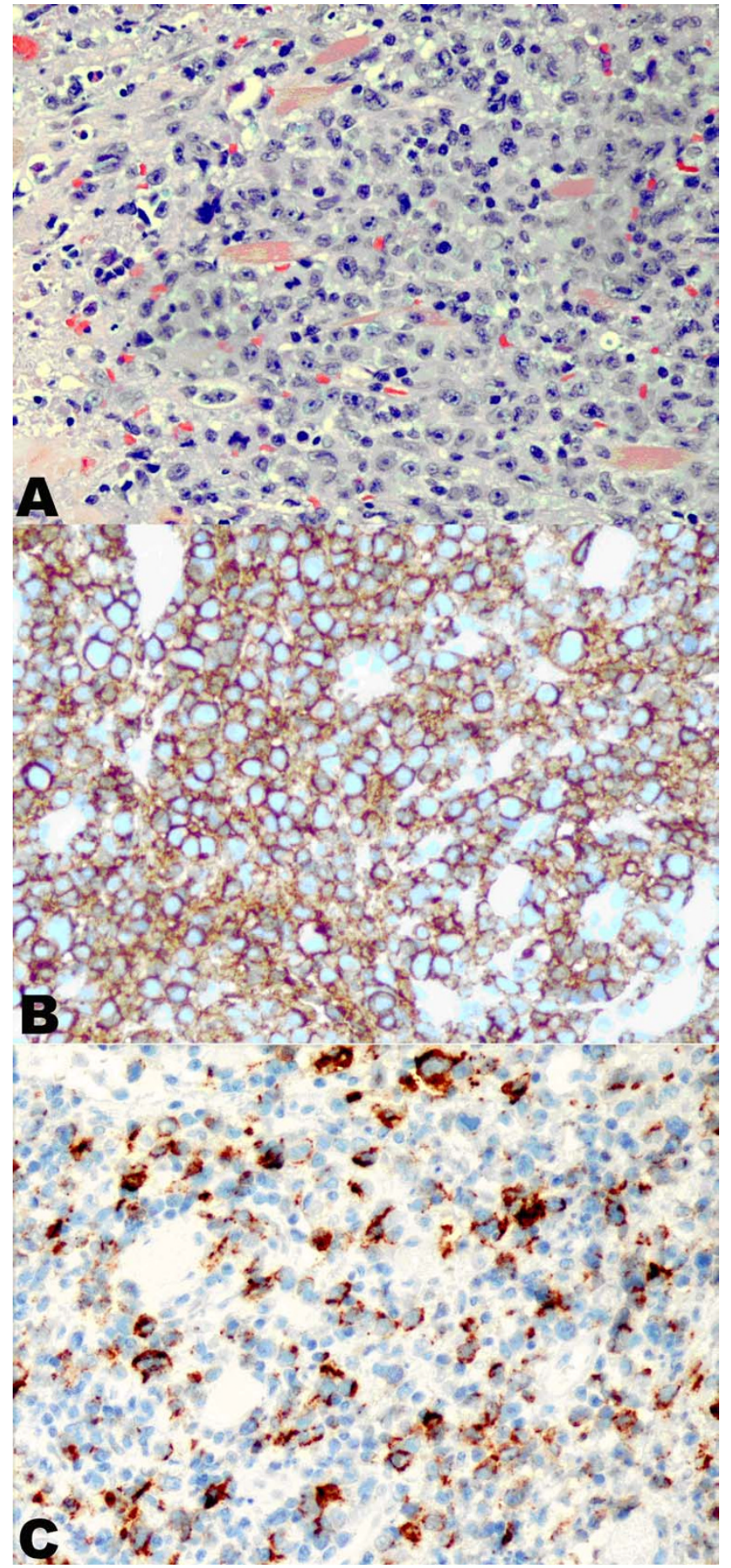

Figure 2

Microphotographs of the monomorphic PTLD. A. Large lymphoid cells with abundant cytoplasm, vesicular nuclei and prominent nucleoli (H\&E, 400x magnification); B. Neoplastic cells positive for CD20 (immunoperoxidase stain, 400× magnification); C. Neoplastic cells positive for EBV LMP (immunoperoxidase stain, $400 \times$ magnification).
Recognition of PTLD as a clinical entity can be traced back to the mid $20^{\text {th }}$ century when the association between host immune response and immunosuppressive therapy with neoplasia was suggested, specially after solid organ transplantation [4-6] However, the development of hematological malignancies following transplantation of solid organs attributed to immunosuppressive therapy was first described by Doak et al [7] in 1968. In this report Doak and colleagues presented a 34 year-old man with history of renal transplantation who was treated with azathioprine and prednisone. Six months after the transplant, the patient presented with oral ulcers, which grew Candida species, and were initially treated with antimycotic medication. He died a month thereafter. Autopsy revealed multiple oral cavity, tongue, esophageal, and hepatic lesions that were composed of polygonal lymphoid cells with scant pale cytoplasm and large hyperchromatic nuclei. These were associated with occasional foci of necrosis, multinucleation, viral inclusions, macronucleoli and mitoses. At the time, it was referred to as reticular cell sarcoma.

In 1969 Penn et al [5] reported a case of a renal transplant patient on azathioprine and prednisone who developed a rapidly progressive left hemiparesis. Brain biopsy revealed a tumor of lymphoid origin. The patient was given radiotherapy with synchronous dosage reduction of the immunosuppressive therapy. He demonstrated marked neurologic improvement with shrinkage of the mass. Two decades later Starlz et al [8] first used the term post-transplant lymphoproliferative disorder (PTLD) and suggested that reduction and/or discontinuation of immunosupressive medications could lead to regression of the posttransplant malignancies.

Stadlmann et al [9] presented a 65-year-old male patient who had undergone kidney transplant in March of 1996. Twenty months later, he developed a small ulcer on the posterior aspect of the pharynx. The patient was serologically positive for EBV, and was on cyclosporine, prednisolone and azathriopine. Biopsy of the ulcer was diagnosed as a posttransplant associated NK/T cell lymphoma. Cyclosporine was subsequently discontinued and 4 cycles of chemotherapy with CHOP (cyclophosphamide, doxorubicin, vincristine and prednisone) were given. A three years' follow up revealed that the patient was still in remission.

In 2003, Reams et al published a series of 400 recipients of lung and/or heart transplant; among them 10 patients developed PTLD. Of particular interest was a 16-year-old female patient who had a history of cystic fibrosis status post bilateral lung transplantation and who was negative for EBV. Her immunosuppressive regimen consisted of cyclosporine A, azathioprine and metylprednisolone. 
Three-hundred and thirty days after the transplant the patient developed a lesion in the left base of tongue. She was diagnosed to have a polymorphic B-cell PTLD. After 4 cycles of rituximab, the patient died of sepsis.

In 2004 Rolland et al [10] reported two cases of oral PTLD in two patients with heart transplantation. The first patient was a 60-year-old male who was immunosupressed with azathriopine, cyclosporin, and prednisolone. During the first ten years following transplantation he had multiple episodes of gingival swelling that were attributed to cyclosporin. Biopsy of the gingiva demonstrated EBVdriven peripheral T-cell lymphoma, NOS. Azathrioprine was discontinued and cyclosporin was decreased. The patient was in remission for one year after the immunosupression adjustment. The second patient was a 61-yearold man who was on azathriopine, cyclosporin and prednisolone, and developed swelling of the maxilla and gingiva. Biopsy showed an EBV-driven diffuse large B-cell lymphoma with focal plasmablastic differentiation. The immunosuppressive therapy was adjusted and subsequently had two recurrences at 6 and 17 months post transplantation, which were treated effectively by stepwise decrease of cyclosporin.

Bruce et al [11] in 2006 presented a case of a 45 -year-old female patient who was status post pancreatic transplantation and on an immunosuppressive regimen consisting of sirolimus, tacrolimus, and prednisone for 22 months. She presented with an ulcer on the ventral aspect of the tongue. Differential diagnosis of the lesion included granuloma of the tongue, infection and drug induced ulceration. Sirolimus was discontinued, tacrolimus was adjusted and a superficial biopsy was obtained. The biopsy revealed a traumatic granuloma with rare EBV+ lymphocytes by in-situ hybridization (EBER). Subsequently the entire lesion was resected and diagnosed as monomorphic EBV-associated PTLD, diffuse large B-cell lymphoma. The patient was followed for two years and was still in remission, but developed chronic rejection of the allograft.

Transplant recipients have a five-fold increased risk of developing de novo head and neck malignancies when compared to general population $[12,13]$, of which the most common neoplasms are skin cancers $[13,14]$ In the transplant population the incidence of PTLD is approximately $2 \%[11,15]$. PTLD is a spectrum of lymphoproliferative disorders in patients who have undergone solid organ or bone marrow transplantation in the setting of immunosuppression [16], with EBV implicated in 2-5\% of adult patients [3] and of up to $20 \%$ of pediatric patients [16]. In the latter population it has been suggested that EBV-associated adenotonsilar enlargement could be a precursor to PTLD [17]. On average, patients have been diag- nosed 2 years after transplantation [13]. In these patients, immunosuppression decreases the immunosurveillance of EBV-specific T-cells; and thus allows subsequent proliferation of EBV-infected B-cells [18-20]. Early development of PTLD is often associated with EBV infection and thus responds to reduction in immunosupression. However, later onset PTLD does not respond to reduced immunosuppression [20]. Later onset EBV-negative PTLD has also been reported and generally has a more aggressive clinical course [18-20].

The organs involved by PTLD vary depending on the difference in immunosuppressive regimens. The allograft itself is involved in only $25 \%$ of the cases [19]. Patients treated with tacrolimus often develop nodal and gastrointestinal PTLD $[2,18]$. In our patient, PTLD developed in the tongue as well as the possible lymph node (cervical and mesenteric) and gastrointestinal tract (as demonstrated by CT scan). Although the oral cavity may be regarded as the uppermost part of the gastrointestinal tract, reports of PTLD involvement of the tongue are extremely rare.

Initial treatment for PTLD is to reduce immunosupression [1]. A response is usually seen within 2-4 weeks of withdrawal of immunosupression [21], and reduction in immunosupression alone leads to long-term disease-free remission in $25-73 \%$ of adults $[15,22]$. The chances of complete remission seem to be directly related to the degree of differentiation of the neoplasm. Early and infectious mononucleosis-like lesions tend to regress more often with reduction in immunosupression alone, compared to monomorphic PTLD. A proportion of cases of both types, however, requires chemotherapy [23]. The benefit of withdrawing immunosupression and the risk of transplant rejection need to be carefully reconciled. The institution of chemotherapy also brings inherent risks of infections and de novo malignancies. Antiviral agents seem to have some effects on the early hyperplasic lesions $[24,25]$. However, these agents do not have significant effects on the lesion once monoclonality has emerged [26].

Although lymphoid malignancies of the tongue and oral cavity have previously been reported [27-30], complete remission of diffuse large B-cell lymphoma after withdrawal of immunosupression has rarely been documented, particularly in cases of PTLD. A consensus in the treatment of PTLD with maximum safety to the organ allograft is yet to be attained. However, the current report demonstrates the efficacy of reduction of immunosupression in the management of some cases of EBV-driven PTLD, even in the form of a high-grade diffuse large B-cell lymphoma. 
Another common dilemma is differentiation opportunistic infections and PTLD. Patients with immunosupression after organ transplantation are at increased risk of infections and sepsis [31]. However, it should be noted that opportunistic infections with positive tissue and/or blood cultures might mask an underlying hematological malignancy $[4,6,7,23]$. Since immunosupressed patient are at increased risk of developing opportunistic infections and hematological malignancies, both possibilities need to be considered on the differential diagnosis. This case report stresses the importance of obtaining biopsies of oral cavity lesions in immunosuppressed patients following solid organ transplantation to direct appropriate treatment in a expeditious fashion.

\section{References}

I. Taylor AL, Marcus R, Bradley JA: Post-transplant lymphoproliferative disorders (PTLD) after solid organ transplantation. Crit Rev Oncol Hematol 2005.

2. Preiksaitis JK: New developments in the diagnosis and management of posttransplantation lymphoproliferative disorders in solid organ transplant recipients. Clin Infect Dis 2004, 39(7): 1016-1023.

3. Allen U, Hebert D, Moore D, Dror Y, Wasfy S: Epstein-Barr virusrelated post-transplant lymphoproliferative disease in solid organ transplant recipients, 1988-97: a Canadian multi-centre experience. Pediatr Transplant 200I, 5(3): 198-203.

4. Burnet FM: Immunological aspects of malignant disease. Lancet 1967, I(750 I): II7I-II74.

5. Penn I, Hammond W, Brettschneider L, Starzl TE: Malignant lymphomas in transplantation patients. Transplant Proc 1969, I(I):106-112.

6. Swanson MA, Schwartz RS: Immunosuppressive therapy. The relation between clinical response and immunologic competence. N Engl J Med 1967, 277(4): I63-I70.

7. Doak PB, Montgomerie JZ, North JD, Smith F: Reticulum cell sarcoma after renal homotransplantation and azathioprine and prednisone therapy. Br Med J I 968, 4(5633):746-748.

8. Starzl TE, Nalesnik MA, Porter KA, Ho M, Iwatsuki S, Griffith BP, Rosenthal JT, Hakala TR, Shaw BW Jr., Hardesty RL, et al.: Reversibility of lymphomas and lymphoproliferative lesions developing under cyclosporin-steroid therapy. Lancet 1984, I(8377):583-587.

9. Stadlmann S, Fend F, Moser P, Obrist P, Greil R, Dirnhofer S: Epstein-Barr virus-associated extranodal NK/T-cell lymphoma, nasal type of the hypopharynx, in a renal allograft recipient: case report and review of literature. Hum Pathol 200I, 32(II): 1264-I268.

10. Rolland SL, Seymour RA, Wilkins BS, Parry G, Thomason JM: Posttransplant lymphoproliferative disorders presenting as gingival overgrowth in patients immunosuppressed with ciclosporin. A report of two cases. J Clin Periodontol 2004, 3I(7):58I-585.

11. Bruce AJ, Subtil A, Rogers RS 3rd, Castro LA: Monomorphic Epstein-Barr virus (EBV)-associated large B-cell posttransplant lymphoproliferative disorder presenting as a tongue ulcer in a pancreatic transplant patient. Oral Surg Oral Med Oral Pathol Oral Radiol Endod 2006, 102(4):e24-8.

12. European best practice guidelines for renal transplantation. Section IV: Long-term management of the transplant recipient. IV.6.2. Cancer risk after renal transplantation. Skin cancers: prevention and treatment. Nephrol Dial Transplant 2002, 17 Suppl 4:3I-36.

13. Gourin CG, Terris DJ: Head and neck cancer in transplant recipients. Curr Opin Otolaryngol Head Neck Surg 2004, 12(2): $122-126$.

14. Penn I: Tumors after renal and cardiac transplantation. Hematol Oncol Clin North Am 1993, 7(2):43I-445.

15. Tsai DE, Hardy CL, Tomaszewski JE, Kotloff RM, Oltoff KM, Somer BG, Schuster SJ, Porter DL, Montone KT, Stadtmauer EA: Reduc- tion in immunosuppression as initial therapy for posttransplant lymphoproliferative disorder: analysis of prognostic variables and long-term follow-up of $\mathbf{4 2}$ adult patients. Transplantation 200I, 7 I(8): 1076-1088.

16. Raj $R$, Frost $A E$ : Lung retransplantation after posttransplantation lymphoproliferative disorder (PTLD): a single-center experience and review of literature of PTLD in lung transplant recipients. J Heart Lung Transplant 2005, 24(6):67|-679.

17. Shapiro NL, Strocker AM: Adenotonsillar hypertrophy and Epstein-Barr virus in pediatric organ transplant recipients. Laryngoscope 200 I, I I I(6):997-100 I.

18. Ferry JA, Jacobson JO, Conti D, Delmonico F, Harris NL: Lymphoproliferative disorders and hematologic malignancies following organ transplantation. Mod Pathol 1989, 2(6):583-592.

19. Harris NL S SH, Frizzera, G, Knowles DM.: Post-transplant lymphoproliferative disorder. In World Health Organization Classification of Tumours: Pathology and genetics of tumours of haematopoietic and lymphoid tissues Edited by: Jaffe ES HNLSHVJW. Lyon , IARC; 200I:264-269.

20. Lim WH, Russ GR, Coates PT: Review of Epstein-Barr virus and post-transplant lymphoproliferative disorder post-solid organ transplantation. Nephrology (Carlton) 2006, I I(4):355-366.

21. Green M, Michaels MG, Webber SA, Rowe D, Reyes J: The management of Epstein-Barr virus associated post-transplant lymphoproliferative disorders in pediatric solid-organ transplant recipients. Pediatr Transplant 1999, 3(4):27I-28I.

22. Gottschalk S, Rooney CM, Heslop HE: Post-transplant lymphoproliferative disorders. Annu Rev Med 2005, 56:29-44.

23. Penn I: The changing pattern of posttransplant malignancies. Transplant Proc 1991, 23(I Pt 2): I I0I-I 103.

24. Stern M, Herrmann R, Rochlitz C, Dirnhofer S, Pless M: A case of post-transplant lymphoproliferative disease presenting as CD20-expressing, Epstein-Barr-virus positive Hodgkin lymphoma. Eur J Haematol 2005, 74(3):267-270.

25. Buadi FK, Heyman MR, Gocke CD, Rapoport AP, Hakimian R, Bartlett ST, Sarkodee-Adoo C: Treatment and outcomes of posttransplant lymphoproliferative disease: a single institution study. Am J Hematol 2007, 82(3):208-2। 4.

26. Paya CV, Fung JJ, Nalesnik MA, Kieff E, Green M, Gores G, Habermann TM, Wiesner PH, Swinnen JL, Woodle ES, Bromberg JS: Epstein-Barr virus-induced posttransplant lymphoproliferative disorders. ASTS/ASTP EBV-PTLD Task Force and The Mayo Clinic Organized International Consensus Development Meeting. Transplantation 1999, 68(10):1517-1525.

27. Derk CT, Conway RT, Jimenez SA: Primary B-cell lymphoma of the tongue in a patient with systemic sclerosis. Oral Oncol 2004, 40(I): 103-106.

28. Manolopoulos L, Nikolopoulos TP, Yiotakis J, Karapatsas J, Maris A, Ferekidis E: Burkitt's lymphoma in the base of the tongue: differential diagnosis and management. ORLJ Otorhinolaryngol Relat Spec 2003, 65(4):226-229.

29. Mate JL, Navarro JT, Ariza A, Ribera JM, Castella E, Junca J, Tural C, Nomdedeu JF, Bellosillo B, Serrano S, Granada I, Milla F, Feliu E: Oral solid form of primary effusion lymphoma mimicking plasmablastic lymphoma. Hum Pathol 2004, 35(5):632-635.

30. Sakabe H, Bamba M, Nomura K, Kitamura S, Segawa H, Yasui H, Inoue T, Taniwaki M, Fujiyama Y, Bamba T: MALT lymphoma at the base of the tongue developing without any background of immunodeficiency or autoimmune disease. Leuk Lymphoma 2003, 44(5):875-878.

31. Kalil AC, Dakroub H, Freifeld AG: Sepsis and Solid Organ Transplantation. Curr Drug Targets 2007, 8(4):533-54I. 